\title{
Economic impact of dengue fever in Latin America and the Caribbean: a systematic review
}

\author{
Andrés Laserna, ${ }^{1}$ Julián Barahona-Correa, ${ }^{1}$ Laura Baquero, ${ }^{1}$ \\ Camilo Castañeda-Cardona, ${ }^{2}$ and Diego Rosselli ${ }^{3}$
}

Suggested citation

Laserna A, Barahona-Correa J, Baquero L, Castañeda-Cardona C, Rosselli D. Economic impact of dengue fever in Latin America and the Caribbean: a systematic review. Rev Panam Salud Publica. 2018;42:e111. https://doi.org/10.26633/RPSP.2018.111

ABSTRACT Objectives. To assess the economic impact of dengue in Latin America and the Caribbean using a systematic review that includes studies not previously considered by other reviews.

Methods. Cochrane methodology was used to conduct a systematic review of the cost of dengue in Latin America. PubMed Central, EMBASE, and the Biblioteca Virtual en Saludwhich includes scientific, peer-reviewed journals not indexed by other databases-were searched from inception through August 2016. All articles that reported cost of illness data for countries in Latin America were included. Included studies underwent a methodological appraisal using a seven-question instrument designed for cost of illness studies. Extracted data were direct and indirect costs for outpatient and hospitalized cases and total cost of the disease. Values were adjusted to 2015 US dollars using the consumer price index.

Results. From a total of 848 initial references, 17 studies were included, mainly from Brazil, Colombia, Cuba, Mexico, and Puerto Rico; costs were available for 39 countries. The methodological appraisal showed that $70 \%$ of the studies met more than $70 \%$ of the evaluated items. The main economic impact of dengue was due to productivity costs. Average annual cost was more than US\$ 3 billion. Direct costs represented over 70\% of the total share for hospitalized cases. For outpatients, direct medical costs were low, but social costs were significant since indirect costs may account for up to $80 \%$ of the total cost.

Conclusions. Dengue fever has a significant economic impact in Latin America. It is essential to develop new public health interventions, such as dengue vaccination, to decrease the propagation of the disease and its total cost.

Keywords Dengue; cost of illness; health care costs; Latin America; Caribbean region.

Dengue virus, an arbovirus transmitted by mosquitoes of the genus Aedes (i.e., A. aegypti and A. albopictus) has

\footnotetext{
School of Medicine, Pontificia Universidad Javeriana, School of Medicine, Bogotá, Colombia. Neuroeconomix, Bogotá, Colombia.

3 Clinical Epidemiology and Biostatistics Department, Pontificia Universidad Javeriana, Medical School, Bogotá, Colombia. Send correspondence to Diego Rosselli, diego.rosselli@gmail.com
}

four serotypes: DEN-1, DEN-2, DEN-3, and DEN-4 (1). Dengue is present in tropical and subtropical areas, often where poor infrastructure and scarce human and technical resources make it hard to control $(1,2)$. The typical clinical presentation of fever, headache, retroocular pain, myalgia, and arthralgia is known as dengue fever without warning signs; the presence of gastrointestinal symptoms and neurological and mucosal bleeding is known as dengue fever with warning signs; and the development of severe hemorrhage, signs of excessive capillary permeability, or organ compromise constitutes severe dengue (3). The rather high mortality of severe dengue (up to $40 \%$ ) can be reduced 
to close to $1 \%$ with adequate medical treatment $(1,2)$.

According to the World Health Organization (WHO), from 50 million 100 million dengue infections and about 20000 dengue-related deaths occur worldwide every year (2). Bhatt and colleagues have estimated an annual average of 390 million infections (4). The incidence in the Region of the Americas increased from 16 per 100000 people in 1980 to 71 per 100000 in $2000-2007$ (5). The cost of the disease is substantial and varies from year to year (6). Two recent studies calculated an annual global cost of US\$ 9 billion (7) - US\$ 39 billion (8).

There have been several efforts to estimate the economic impact of dengue in Latin America. In 2011, Shepard and colleagues (9) published an elegant estimation of the burden of disease for the Americas. It included studies through 2009, but due to the scarcity of data, most of the estimates relied on only two of those studies. Since 2009, a number of relevant studies in different countries have been published. In addition, previous systematic reviews of the topic did not include literature indexed by Latin American databases (9), thus missing important local data in a region where socioeconomic and geographic conditions vary greatly. This new data may allow a more current estimation of the cost of illness for dengue in Latin America.

Furthermore, primary prevention has partially controlled the course of the disease (1). The implementation of preventive measures, such as vaccination, are part of the control agenda; estimates of the burden of disease are required to determine potential impact (10). The objective of this paper was to assess the economic impact of dengue in Latin America and the Caribbean using a systematic review of the literature that includes studies not previously considered.

\section{MATERIALS AND METHODS}

Cochrane methodology was used to conduct a systematic review on the cost of dengue in Latin America and the Caribbean. PubMed Central (U.S. National Library of Medicine, Bethesda, Maryland, United States), EMBASE (Excerpta Medica Database, Elsevier, Amsterdam, the Netherlands), and BVS (Biblioteca Virtual en Salud, Latin American and Caribbean Center on Health Sciences Information, São Paulo, Brazil) were searched, from inception - August 2016. BVS includes scientific literature from Latin America published in peer-reviewed journals not indexed in other databases. The terms used and adapted to each database were ("dengue") AND ("cost* OR economics") AND (each of the countries of Latin America and Caribbean, individually separated by "OR"). Supplemental material on the search strategy is available from the corresponding author upon request.

All cost studies that reported direct or indirect costs associated with dengue fever in Latin America or the Caribbean were included. Studies excluded were those regarding vector control costs, economic evaluations on disease control interventions, and reviews of the literature. No filters were applied.

An electronic form was developed to standardize the data extracted, including the variables of primary interest to the study: direct and indirect costs for outpatient and hospitalized cases and total cost of the disease. Direct costs were defined as expenses related to diagnosis, whether direct medical costs (e.g., hospital admission, diagnostic and treatment costs) or direct non-medical costs (e.g., transportation to the health care facility). Indirect medical costs consisted of productivity losses related to morbidity (11).

Study screening was performed independently by three of the researchers (AL, JBC, LB). Any disagreements on inclusion were discussed until a consensus was reached. To identify any additional, potentially-eligible article, the references of each relevant citation and review were manually examined. After reading the articles in full text, studies on the cost of dengue fever in any Latin American or Caribbean country were analyzed.

Although the best practice for systematic reviews is to perform a risk of bias assessment on all included articles, to the best of our knowledge, no specific tool exists for partial economic evaluations, such as cost of illness studies. Therefore, the study was limited to only examining the methodological quality of the reviewed articles. Methodological quality was assessed based on previously proposed relevant items in cost of illness studies (11). This was determined to be the best option since official, international guidelines for quality analysis of such studies are lacking $(12,13)$, and current, quality assessments of economic studies are not intended to evaluate cost of illness studies (14). The following elements were evaluated: perspective, population, direct cost, indirect cost, discounting, incremental/attributable cost, and sensitivity analysis; for further details, refer to reference (11). These items were appraised by three of the researchers (AL, JBC, LB).

Since the results were presented in local currency or United States dollars of different years, the values were adjusted to 2015 US\$ using the consumer price index. Moreover, to standardize the costs described in the various studies (Table 1) and to summarize them (Table 2), in some cases it was necessary to perform additional calculations based on the original data $(9,17-22)$. Thus, simple averages between the private and public health systems, regions, years, and institutions were calculated. The explanation for each calculation is described in the results section. The results are presented as a narrative synthesis, by country, to allow for a better understanding of the challenges in each and its contribution to the total burden of dengue in Latin America. Countries with at least two articles reporting cost data were described in an extensive manner; those with only one article are presented in Table 2.

\section{RESULTS}

The initial search resulted in 848 unique citations of which 62 were reviewed in full text. Of these, $17(9,15-30)$ provided relevant, useful information (Figure 1) and were included in the analysis (Table 1). Most of these 17 were from Brazil, Colombia, Cuba, Mexico, and Puerto Rico. Altogether, costs were available for 39 countries (Table 2). All of the studies were partial economic evaluations (cost of illness studies). Overall, $70 \%$ of the studies (12 of the 17) met more than $70 \%$ of the evaluated criteria; direct costs and study perspective were reported by all authors; as expected, incremental/attributable costs were not evaluated by any article. A summary of the evaluation is presented in Table 3.

\section{Argentina}

Two studies were included for Argentina. Shepard and colleagues (9) estimated that direct medical costs represented the largest proportion of cost for both outpatient (59\%; US\$ 316 / 536) and hospitalized (58\%; US\$ $820 / 1$ 413) cases. Tarragona and colleagues (20) evaluated 
FIGURE 1. Flow diagram of study selection for a systematic review of the economic impact of dengue fever in Latin America and the Caribbean

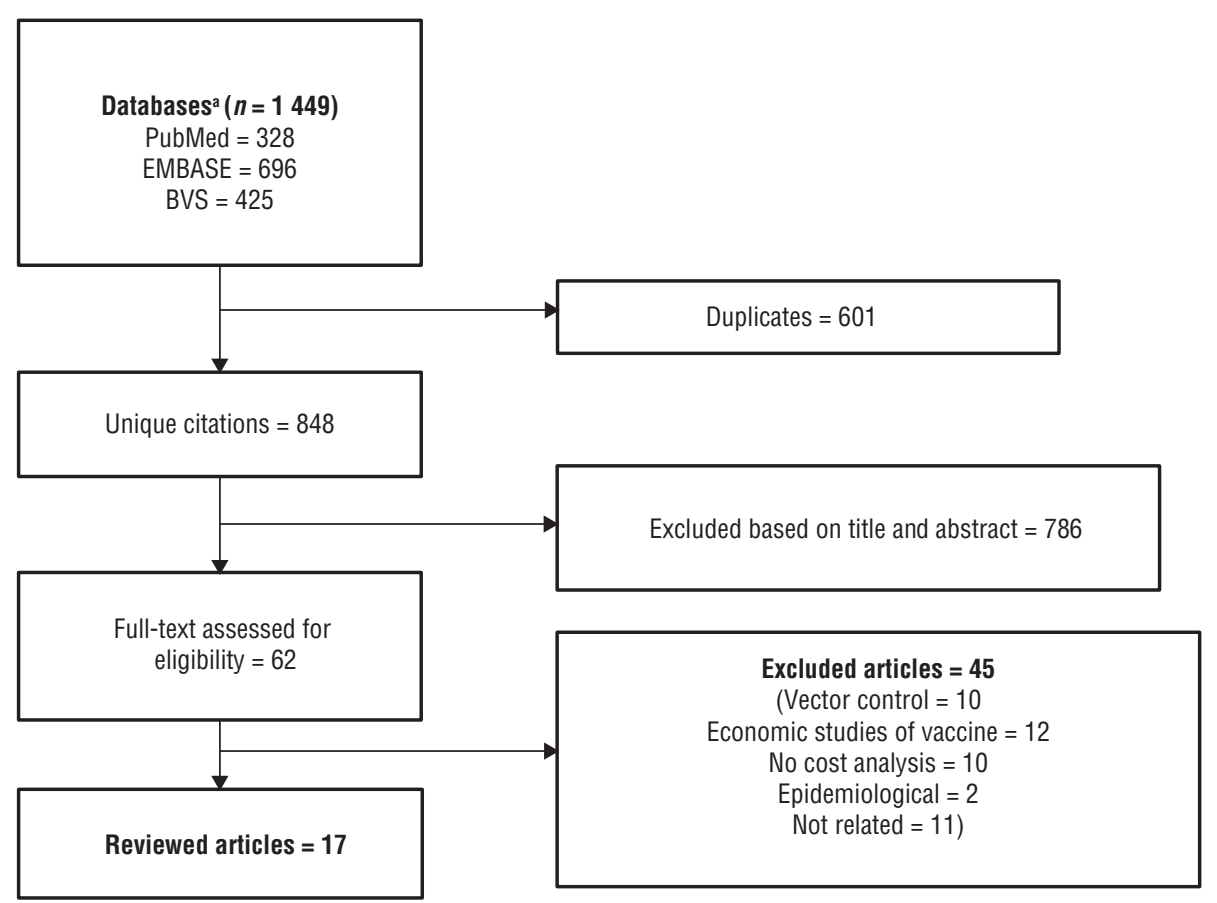

apubMed Central (U.S. National Library of Medicine, Bethesda, Maryland, United States), EMBASE (Excerpta Medica Database, Elsevier, Amsterdam, the Netherlands), and BVS (Biblioteca Virtual en Salud, Latin American and Caribbean Center on Health Sciences Information, São Paulo, Brazil)

Source: Prepared by the authors from study data.

three geographic areas in Argentina and divided the cases into three scenarios: general ward management, specialty care, and intensive care (ICU). In an effort to standardize and to draw comparisons with other studies, the general ward cases were considered to be outpatient; specialty care was considered to be hospitalization; and the ICU cases were considered separately. It was reported that medical costs generated $47 \%$ (US\$ 119 / 253) of total costs for outpatient cases ( $90 \%$ of the total). For the hospitalized cases, medical cost represented the $56 \%$ (US\$ 174 / 308), and for ICU cases, 67\% (US\$ 269 / 403). The costs shown in Table 2 correspond to averages obtained from the three geographic areas. Total costs are shown in Table 2.

\section{Brazil}

Four studies were included for Brazil. Shepard and colleagues (9) reported that outpatient cases represented $78 \%$ of total costs. Direct costs for outpatient cases accounted for $17 \%$ (US\$ 72 / 416), the lowest in the Americas. For hospitalized cases, 43\% (US\$ 413 / 966) were direct and $52 \%$ (US\$ 500 / 966) indirect costs. Suaya and colleagues (15) evaluated the cost of dengue in five countries (Brazil, El Salvador, Guatemala, Panama, and Venezuela). From the perspective of that study, these countries represent $94 \%$ of the total cost in the region. For outpatient cases, indirect costs accounted for 83\% (US\$ 292 / 353) of the total cost, and for hospitalized patients, 52\% (US\$425/ 820). Vieira-Machado and colleagues (22) reported that in the city of Dourados (Mato Grosso do Sul, Brazil), direct medical costs equaled 2.5\% (about US\$ 230000 by 2015) of its per-capita gross domestic product (GDP). Costs in the private sector were $280 \%$ higher than in the public sector. Lastly, Martelli and colleagues (19) reported that $99.5 \%$ of cases corresponded to outpatient cases, where direct costs represented the lowest percentage of the total cost. On the other hand, hospitalized cases accounted for the largest proportion. To standardize the results in Table 2, the averages between the private and public health system or between geographic areas were calculated.

\section{Colombia}

Four studies were included for Colombia. Shepard and colleagues (9) determined that dengue costs increased to US\$ 540 million in the Andean area (Bolivia, Colombia, Ecuador, Peru, and Venezuela). Castro-Rodríguez and colleagues (23) established direct and indirect costs for three periods, including an epidemic period in 2012; all these, from the social perspective. Total costs for 2012 represented $108 \%$ of the immunization program budget, $0.14 \%$ of the national budget, and $0.04 \%$ of the GDP, indicating a substantial economic impact. In a subsequent study, CastroRodríguez and colleagues (30) assessed total cost of the disease from a societal perspective, including prevention and monitoring activities that were corrected for underreporting. Costs were as high as US\$ 341 for 2010; burden of disease expressed in disabilityadjusted life years (DALYs) was reported. Lastly, Castañeda-Orjuela and colleagues (21) estimated that the cost per case and the total cost for dengue (Table 2), including control activities and medical management, exceeded US\$ 60 MM annually; while control strategies surpassed the total costs, representing more than $70 \%$ of the total. Regarding the cost per case, an average was calculated based on the data reported by the authors.

\section{Cuba}

Three studies were included for Cuba. Shepard and colleagues (9) reported indirect costs to be $54 \%$ (US\$ 42 / 78) of the total cost in outpatient cases, whereas in hospitalized cases, most costs were direct (66\%; US\$ 229 / 345). Baly and colleagues (24) estimated the cost of dengue in Guantánamo, and identified lost productivity as the largest proportion of the total cost. The costs of the vector control program were, according to these authors, the highest among dengue fever control programs worldwide (US\$ 1.96 person/month in the non-epidemic period and US\$ 2.21 person/month in the epidemic period). Finally, Valdés and colleagues (17) estimated the costs of the disease during the 1997 epidemic in Santiago de Cuba, reporting that 76\% (US\$ 11500124 / 15138 874) went toward vector control and only 19\% (US\$ 2833301 /15 138 874) to hospital costs. Because the data on cost of dengue fever treatment came from various health centers in Santiago de Cuba, the values in Table 2 are averages. 


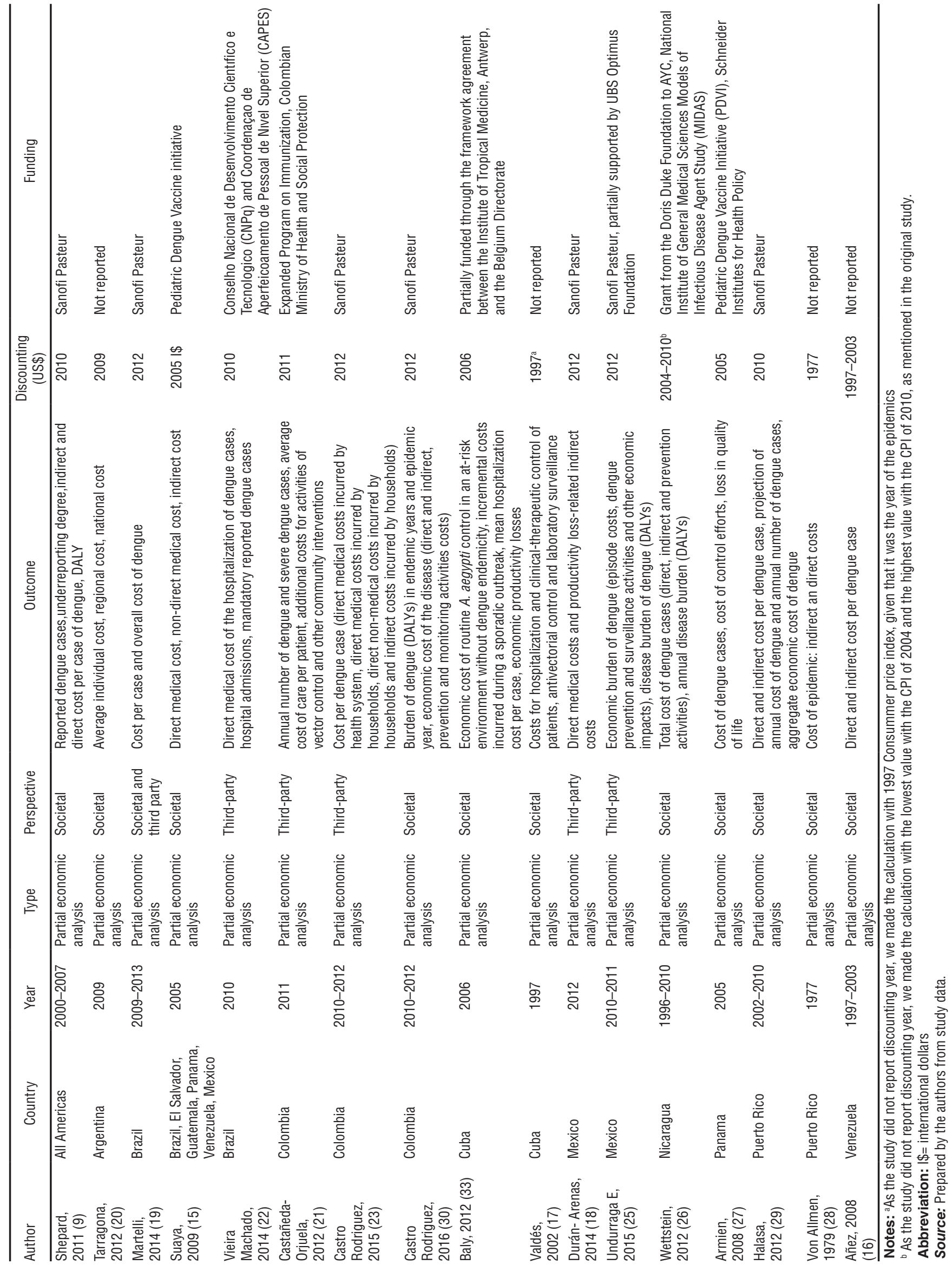


TABLE 2. Cost per ambulatory case, cost per hospitalized case and cost per year reported in each study and country, adjusted to US dollars of 2015

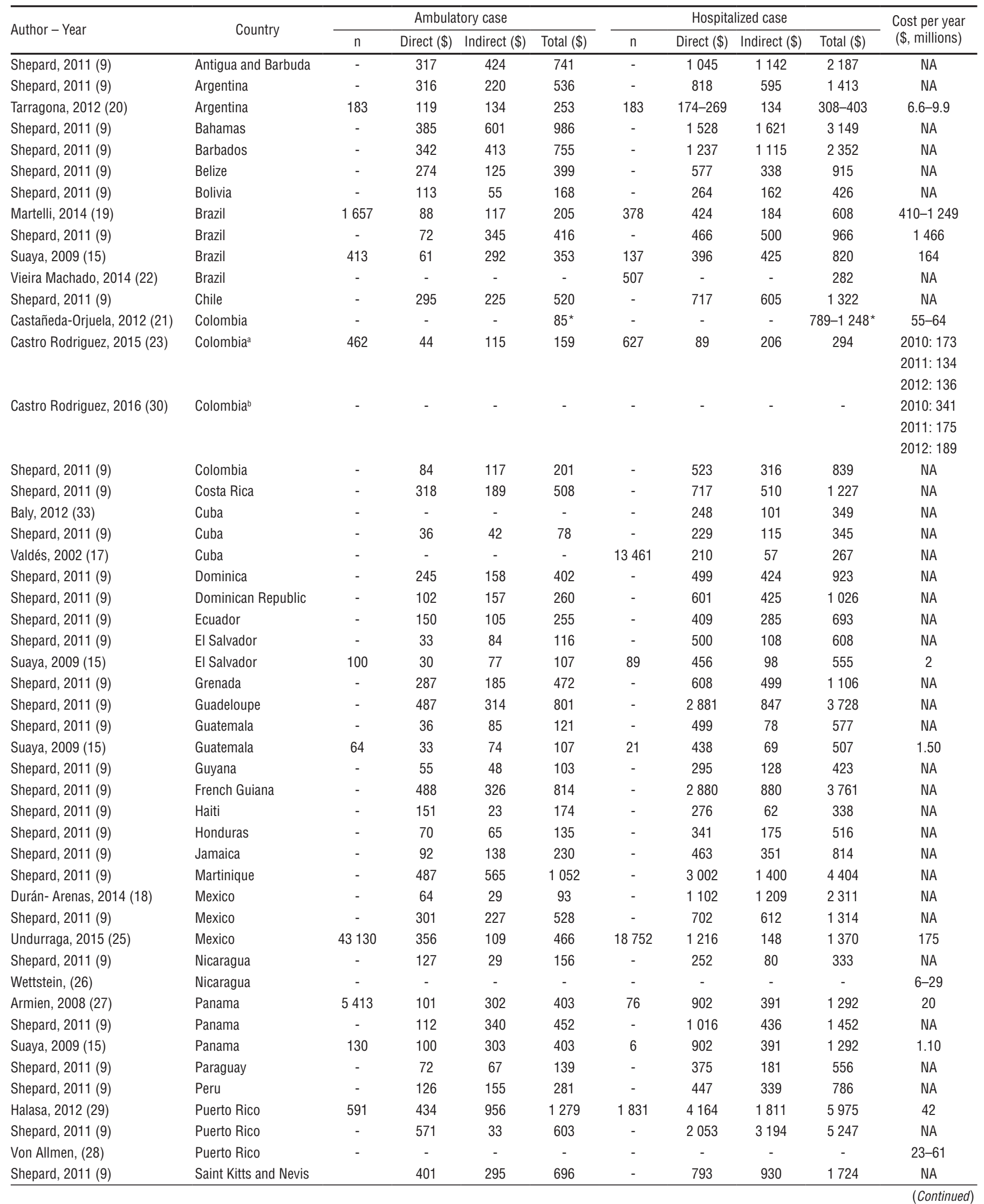


TABLE 2. (Continued)

\begin{tabular}{|c|c|c|c|c|c|c|c|c|c|c|}
\hline \multirow{2}{*}{ Author - Year } & \multirow{2}{*}{ Country } & \multicolumn{4}{|c|}{ Ambulatory case } & \multicolumn{4}{|c|}{ Hospitalized case } & \multirow{2}{*}{$\begin{array}{l}\text { Cost per year } \\
(\$, \text { millions })\end{array}$} \\
\hline & & $\mathrm{n}$ & Direct $(\$)$ & Indirect (\$) & Total $(\$)$ & $n$ & Direct (\$) & Indirect (\$) & Total $(\$)$ & \\
\hline Shepard, 2011 (9) & Saint Lucia & - & 272 & 176 & 448 & - & 554 & 475 & 1029 & NA \\
\hline Shepard, 2011 (9) & $\begin{array}{l}\text { Saint Vincent and } \\
\text { Grenadines }\end{array}$ & - & 95 & 171 & 265 & - & 570 & 461 & 1030 & NA \\
\hline Shepard, 2011 (9) & Suriname & - & 118 & 187 & 305 & - & 683 & 503 & 1186 & NA \\
\hline Shepard, 2011 (9) & Trinidad and Tobago & - & 573 & 576 & 1149 & - & 1546 & 1555 & 3101 & NA \\
\hline Shepard, 2011 (9) & Uruguay & - & 359 & 265 & 624 & - & 838 & 716 & 1554 & NA \\
\hline Añez, 2006 (16) & Venezuela & 26645 & 5 & 16 & 21 & 3606 & 112 & 32 & 137 & 229 \\
\hline Shepard, 2011 (9) & Venezuela & - & 148 & 211 & 360 & - & 1009 & 337 & 1346 & $N A$ \\
\hline Suaya, 2009 (15) & Venezuela & 130 & 84 & 120 & 204 & 70 & 570 & 190 & 761 & NA \\
\hline Shepard, 2011 (9) & $\begin{array}{l}\text { Virgin Islands- } \\
\text { American }\end{array}$ & -- & 152 & 466 & 618 & - & 4849 & 1258 & 6106 & NA \\
\hline Shepard, 2011 (9) & Virgin Islands-British & - & 387 & 1143 & 1530 & - & 2354 & 3090 & 5439 & NA \\
\hline
\end{tabular}

Notes: ${ }^{a}$ From a health system perspective; ${ }^{\mathrm{b}}$ From a societal perspective;

To standardize the results, the averages between the private and public health system, or between regions studied depending on the case, were calculated.

The values were adjusted to 2015 US dollars using the consumer price index (CPI).

Abbreviation: NA, Not available

Source: Prepared by the authors from study data.

TABLE 3. Quality assessment of the included studies

\begin{tabular}{|c|c|c|c|c|c|c|c|c|}
\hline & Perspective & Population & Direct cost & Indirect cost & Discounting & $\begin{array}{l}\text { Incremental / } \\
\text { attributable cost }\end{array}$ & $\begin{array}{l}\text { Sensitivity } \\
\text { analysis }\end{array}$ & Total \\
\hline Shepard, 2011 (9) & + & $(+)$ & + & + & + & NA & + & $86 \%$ \\
\hline Tarragona, 2012 (20) & + & $(+)$ & + & + & + & NA & 0 & $71 \%$ \\
\hline Martelli, 2014 (19) & + & + & + & + & + & NA & + & $86 \%$ \\
\hline Suaya, 2009 (15) & + & + & + & + & + & NA & 0 & $71 \%$ \\
\hline Vieira Machado, 2014 (22) & $(+)$ & + & + & 0 & + & NA & 0 & $57 \%$ \\
\hline Castañeda-Orjuela, 2012 (21) & $(+)$ & 0 & + & 0 & + & NA & $(+)$ & $57 \%$ \\
\hline Castro Rodriguez, 2015 (23) & + & 0 & + & + & + & NA & + & $71 \%$ \\
\hline Castro Rodriguez, 2016 (30) & + & 0 & + & + & + & NA & + & $71 \%$ \\
\hline Baly, 2012 (33) & + & 0 & + & + & + & NA & 0 & $57 \%$ \\
\hline Valdés, 2002 (17) & $(+)$ & + & + & 0 & 0 & NA & 0 & $43 \%$ \\
\hline Durán- Arenas, 2014 (18) & + & $(+)$ & + & + & + & NA & 0 & $71 \%$ \\
\hline Undurraga E, 2015 (25) & + & $(+)$ & + & + & + & NA & + & $86 \%$ \\
\hline Wettstein, 2012 (26) & + & 0 & + & + & 0 & NA & + & $57 \%$ \\
\hline Armien, 2008 (27) & + & $(+)$ & + & + & + & NA & + & $86 \%$ \\
\hline Halasa, 2012 (29) & + & + & + & + & + & NA & + & $86 \%$ \\
\hline Von Allmen, 1979 (28) & + & $(+)$ & + & + & $(+)$ & NA & $(+)$ & $86 \%$ \\
\hline Añez, 2008 (16) & + & $(+)$ & + & + & $(+)$ & NA & 0 & $71 \%$ \\
\hline
\end{tabular}

Nomenclature: + present; (+) partly fulfilled; 0 absent; NA, not applicable.

Source: Prepared by the authors from study data.

\section{Mexico}

Three studies were included for Mexico. Shepard and colleagues (9) estimated that Mexico incurred $7 \%$ of the total dengue fever cost in the Americas for 2007. Outpatient cases, given their greater frequency, generated the greatest economic impact. Durán-Arenas and colleagues (18) found out that the "real" management costs differed widely from the costs calculated with an "ideal" treatment scheme, both in the public and private systems. They associated these with failures in the health system. Regarding the indirect costs, they highlighted higher out-of-pocket costs for patients in the public system. The costs per case are found in Table 2 and correspond to an average of the real values in both health systems. Lastly, Undurraga and colleagues (25) estimated that the indirect cost per case of fatal dengue exceeded US\$ 60000.

\section{Nicaragua}

Two studies were included for Nicaragua. Shepard and colleagues (9) estimated that direct medical costs for both outpatient and hospitalized cases represented most of the total costs $(81 \%$ (US\$ 127 / 156) and 76\% (US\$ 252 / 333), 
respectively). Wettstein and colleagues (26) calculated that of the total cost of dengue in 1996 - 2010, including prevention activities, outpatient cases $(81 \%-99 \%)$ made up the majority. Indirect costs were as high as $50 \%$ of total costs, attributed mainly to years of premature death.

\section{Panama}

Two studies were included for Panama. Shepard and colleagues (9) identified indirect costs to be 75\% (US\$ 340 / 452) in outpatient cases. By contrast, in hospitalized cases, indirect costs were only 30\% (US\$ 436 / 1 452). Armien and colleagues (27) estimated similar proportions for outpatient and hospitalized cases in an epidemic year, with the cost of dengue control and surveillance at $30 \%$ of the total.

\section{Puerto Rico}

Three studies were included for Puerto Rico. Shepard and colleagues (9) reported direct medical costs to be $95 \%$ (US\$ 571 / 603) of the total cost per outpatient case. By contrast, indirect costs were the largest proportion of the total cost per hospitalized case (61\%; US\$3 194 / 5 247). Von Allmen and colleagues (28) reported that direct costs exceeded US\$ 18 million, while indirect costs were as high as US\$ 42 million; hospital costs of complicated cases were not included. Halasa and colleagues (29) reported that the proportion of direct and indirect costs were similar, with 48\% (US\$20 103 / 42 113) versus 50\% (US\$ 21167 / 42 113) of total costs, respectively. However, the indirect costs were higher in outpatient (75\%; US\$ 956 / 1 279) than in inpatient cases (30\%; US\$ 1811 / 5 975), for which direct costs accounted for the highest burden. Hospitalized cases represented $63 \%$ (US\$ $26380 / 42113$ ) of the total cost, and fatal cases represented 18\% (US\$ 7516 / 42 113), with a cost per case exceeding US\$ 460000 .

\section{Venezuela}

Two studies were included for Venezuela. Shepard and colleagues (9) reported that Venezuela, with $15 \%$ of the total cost, was one of the main contributors to the economic burden of dengue in the Americas. Indirect costs were the largest proportion in outpatient cases
(59\%; US\$ 211 / 360). In hospitalized cases, direct medical costs accounted for the largest proportion (75\%; US\$ 1009 / $1346)$. Añez and colleagues (16) found that $65 \%$ were indirect costs. In order to analyze the results obtained by these authors, it was necessary to calculate the indirect costs according to the number of days of absenteeism, multiplied by the minimum wage in 1997 - 2003. The grand total was divided by 7 (years) to determine the average annual cost.

\section{DISCUSSION}

The incidence of dengue fever has increased substantially due to several factors including population growth, urbanization, tourism, global warming, forced displacement, barriers to preventive care, and geographic conditions that delay government interventions (31).

The economic cost of dengue in Latin America is high, exceeding US\$ 3 billion annually; in some countries, such as Brazil, it may be as high as US\$ 1.4 billion annually. Although most cases are managed in the outpatient setting, the indirect costs represent the largest proportion of the total share, and thus, a high burden for society. In contrast, the costs of a hospitalized case are mostly direct medical costs that generate a heavy burden on health systems. Despite uncertainty on the real incidence due to underreporting of dengue in the region, all of the studies highlight its high economic impact. Different methodologies have been used in the various studies, which make it tough to establish comparisons. Moreover, several authors have reported that surveillance and vector control programs represent a major economic share of dengue's cost of illness (17, 27, $32-39)$.

The estimation of a high cost for Latin America is consistent with the large number of annual cases. Bhatt and colleagues (4) estimated more than 13 million apparent cases (i.e., any level of clinical severity), comprising $14 \%$ of cases worldwide in 2010, far fewer than Asia (70\%). However, this proportion could be $40 \%$ if unapparent cases were included (i.e., oligo or asymptomatic). Along these lines, Shepard and colleagues (7) estimated a total cost for Latin America of US\$ 1.7 billion for 2013; they argued that the reduction in the total cost from the US\$ 3 billion estimate of their previous study (9) was due to the fact that very few cases of unapparent dengue fever receive medical attention. On the other hand, Selck and colleagues (8) estimated a cost for the Americas in 2011 of up to US\$ 10 billion, which would correspond to $25 \%$ of the world total.

The studies included in this review report that about $90 \%$ of the dengue cases are ambulatory, and that these account for the largest proportion of the total cost in Latin America. This estimation was confirmed by Shepard and colleagues using different data sources; however, this behavior has not been observed in Asia, where the costs of hospitalization are higher, nor in Africa, where the costs for fatal cases are dominant (7). The proportion of indirect costs tends to be higher for outpatient cases in all Latin American countries, which negatively impacts individual, family, and societal productivity. Nonetheless, these costs may be higher: some studies estimate that the total costs could increase by $13 \%$ due to persistent symptoms $(40,41)$.

Regarding hospitalized cases of dengue in Latin America, costs may vary from US\$ 130 - US\$ 5 000. This wide range appears to be related to differences in medical services costs that could explain why direct medical costs represent the largest proportion (50\%) of the total share. These cases do not seem to exceed $5 \%$ of the total, but their cost is about $10 \%$ of the total cost in the region (7). This proportion is small compared to Asia, where hospitalized cases represent $60 \%$ of the total cost (7). In addition, indirect costs and fatal cases-which yield hospitalization costs before the fatal outcome-represent the remaining $50 \%$ of the grand total and generate an important burden for society. Shepard and colleagues determined a cost per fatal case of up to US\$ 80000 (7), close to the figures reported by the studies included in this review.

A review of disease burden of dengue as measured by DALY and quality adjusted life years (QALY) was avoided given the heterogeneity in the applied methodologies. Stanaway and colleagues (42) have estimated 1.14 million DALY lost worldwide. According to the studies included in this review, in Nicaragua the lost DALY were from 99 - 805 per million inhabitants (26); in Colombia, from 83 - 199 (30); and in Mexico, 65 (25). Shepard and colleagues (9) estimated lost DALYs for all the regions along the continent. The impact evaluation was performed from both the societal and 
health system perspectives. The burden of disease differed between countries according to: (a) the number of people infected; (b) the medical costs in each system; and (c) the economic potential of each citizen relative to the national GDP. About $60 \%$ of dengue fever costs for the region are the result of indirect costs, expressed in the loss of productivity due to non-fatal dengue cases (9).

Limitations. Certain shortcomings of this study should be considered. The lack of a specific risk of bias tool for partial economic evaluations limited the review to a methodological quality appraisal. In addition, variations in the methodology of cost estimation hindered stronger comparisons. These differences were probably due to the definition of cost categories, sources of information, the inherent difficulties in estimating the extent of underreporting, among others; for example, in most studies the treatment type was not described nor was the criteria for classifying a case as requiring hospitalization or ICU care. Constenla and colleagues (43) considered that much of the heterogeneity in economic studies of dengue fever is due to an absence of methodological guidelines. Although specific guidelines exist for endemic countries in the Americas, socioeconomic and geopolitical specifics limit the ability to collect economic and clinical information and favor underreporting of cases (43).

The included studies also did not address other factors, such as dengue's effect on tourism, as evidenced at the FIFA World Cup of Brazil (44). In what is a coincidence between studies, the magnitude of dengue's impact highlights the need to implement public health measures for its prevention. Cost studies will allow future economic analyses of possible interventions, such as vector control and vaccination of selected population groups. An example of such an analysis was carried out by the Mexican Group of Dengue Fever Experts, which analyzed the effects of a vaccination program in Mexico (10).

\section{Conclusions}

The share distribution of the cost of dengue differs among countries, underscoring the socioeconomic and geographic differences among countries of Latin America. However, local data for most countries is unavailable and a call for action to address this gap is pivotal. Of note is that much of the information available for many countries was based on extrapolated data from other nations, which helps partially on decision making. To understand its impact, the implementation of any dengue prevention and control interventions, such as vaccination, requires current data on the cost of illness for each country. Additionally, vector control and education in at-risk communities are cornerstones of preventing not just dengue fever, but also emerging and reemerging diseases such as Chikungunya, Mayaro, and Zika that share a common vector.

\section{Conflict of interests: None declared.}

Disclaimer. Authors hold sole responsibility for the views expressed in the manuscript, which may not necessarily reflect the opinion or policy of the RPSP/ PAJPH and/or PAHO.

\section{REFERENCES}

1. Simmons CP, Farrar JJ, Nguyen van VC, Wills B. Dengue. N Engl J Med. 2012;366(15): 1423-32.

2. World Health Organization. Dengue: guidelines for diagnosis, treatment, prevention and control. Geneva: WHO; 2009.

3. Malagon JN, Padilla JC, Rojas-Alvarez DP. Guía de atención clínica integral del paciente con Dengue. Infection. 2011;15(4): 293-301.

4. Bhatt S, Gething PW, Brady OJ, Messina JP, Farlow AW, Moyes CL, et al. The global distribution and burden of dengue. Nature. 2013;496(7446):504-7.

5. San Martín JL, Brathwaite O, Zambrano B, Solórzano JO, Bouckenooghe A, Dayan $\mathrm{GH}$, et al. The epidemiology of dengue in the Americas over the last three decades: a worrisome reality. Am J Trop Med Hyg. 2010;82(1):128-35.

6. Halstead SB, Suaya JA, Shepard DS. The burden of dengue infection. Lancet. 2007; 369(9571):1410-1.

7. Shepard DS, Undurraga EA, Halasa YA, Stanaway JD. The global economic burden of dengue: a systematic analysis. Lancet Infect Dis. 2016;16(8):935-41.

8. Selck FW, Adalja AA, Boddie CR. An estimate of the global health care and lost productivity costs of dengue. Vector-borne Zoonotic Dis. 2014;14(11):824-6.

9. Shepard DS, Coudeville L, Halasa YA, Zambrano B, Dayan GH. Economic impact of dengue illness in the Americas. Am J Trop Med Hyg. 2011;84(2):200-7.
10. Betancourt-Cravioto M, Kuri-Morales $P$, González-Roldán JF, Tapia-Conyer R, Mexican Dengue Expert Group. Introducing a dengue vaccine to Mexico: development of a system for evidence-based public policy recommendations. PLoS Negl Trop Dis. 2014;8(7):e3009.

11. Politiek K, Oosterhaven JAF, Vermeulen KM, Schuttelaar M-LA. Systematic review of cost-of-illness studies in hand eczema. Contact Dermatitis. 2016;75(2):67-76.

12. Drummond MF, Sculpher MCK et al. Critical assessment of economic evaluation. In: Methods for the Economic Evaluation of Health Care Programmes. 4th ed. New York: Oxford University Press; 2015. Pp. 41-76.

13. Zhu TY, Tam LS, Li EK. Cost-of-illness studies in systemic lupus erythematosus: A systematic review. Arthritis Care Res (Hoboken). 2011;63(5):751-60.

14. Wijnen B, Van Mastrigt G, Redekop WK, Majoie H, De Kinderen R, Evers S. How to prepare a systematic review of economic evaluations for informing evidence-based healthcare decisions: data extraction, risk of bias, and transferability (part 3/3). Expert Rev Pharmacoecon Outcomes Res. 2016;16(6):723-32.

15. Suaya JA, Shepard DS, Siqueira JB, Martelli CT, Lum LCS, Tan LH, et al. Cost of dengue cases in eight countries in the Americas and Asia: a prospective study. Am J Trop Med Hyg. 2009;80(5): 846-55.
16. Añez G, Balza R, Valero N, Larreal Y. Economic impact of dengue and dengue hemorrhagic fever in the State of Zulia, Venezuela, 1997-2003. Rev Panam Salud Publica. 2006;19(5):314-20.

17. Valdés G, Vila Mizhrahi J, Guzmán M. Impacto económico de la epidemia de dengue 2 en Santiago de Cuba, 1997. Rev Cuba Med Trop. 2002;54(3):220-7.

18. Durán-Arenas L, Zubieta-Zavala A, LópezCervantes M. Medical costs of dengue fever in Mexico. Am J Trop Med Hyg. 2014;91(5_Suppl 1):1401.

19. Martelli CMT, Siqueira JB, Parente MPPD, Zara AL de SA, Oliveira CS, Braga C, et al. Economic impact of dengue: multicenter study across four Brazilian regions. PLoS Negl Trop Dis. 2015;9(9):e0004042.

20. Tarragona S, Monteverde M, Marchioni S, Caporale J, Pereiro A, Palacios J. Dengue en la Argentina, un análisis económico del impacto de la epidemia de 2009. Salud Colect. 2009;8(2):151-62.

21. Castañeda-Orjuela C, Díaz H, AlvisGuzman N, Olarte A, Rodriguez H, Camargo G, et al. Burden of disease and economic impact of dengue and severe dengue in Colombia, 2011. Value Heal Reg Issues. 2012;1(2):123-8

22. Vieira Machado AA, Estevan AO, Sales A, Brabes KC da S, Croda J, Negrão FJ. Direct costs of dengue hospitalization in Brazil: public and private health care systems and use of WHO guidelines. PLoS Negl Trop Dis. 2014;8(9):e3104. 
23. Castro Rodriguez R, Galera-Gelvez K, López Yescas JG, Rueda-Gallardo JA. Costs of dengue to the health system and individuals in Colombia from 2010 to 2012. Am J Trop Med Hyg. 2015;92(4):709-14.

24. Baly A, Toledo ME, Rodriguez K, Benitez JR, Rodriguez M, Boelaert M, et al. Costs of dengue prevention and incremental cost of dengue outbreak control in Guantanamo, Cuba. Trop Med Int Health. 2012;17(1): 123-32.

25. Undurraga EA, Betancourt-Cravioto $M$, Ramos-Castañeda J, Martínez-Vega R, Méndez-Galván J, Gubler DJ, et al. Economic and disease burden of dengue in Mexico. PLoS Negl Trop Dis. 2015;9(3): e0003547.

26. Wettstein ZS, Fleming M, Chang AY, Copenhaver DJ, Wateska AR, Bartsch SM, et al. Total economic cost and burden of dengue in Nicaragua: 1996-2010. Am J Trop Med Hyg. 2012;87(4):616-22.

27. Armien B, Suaya JA, Quiroz E, Sah BK, Bayard V, Marchena L, et al. Clinical characteristics and national economic cost of the 2005 dengue epidemic in Panama. Am J Trop Med Hyg. 2008;79(3):364-71.

28. Von Allmen SD, López-Correa RH, Woodall JP, Morens DM, Chiriboga J, Casta-Velez A. Epidemic dengue fever in Puerto Rico, 1977: a cost analysis. Am J Trop Med Hyg. 1979;28(6):1040-4.

29. Halasa YA, Shepard DS, Zeng W. Economic cost of dengue in Puerto Rico. Am J Trop Med Hyg. 2012;86(5):745-52.

30. Castro Rodríguez R, Carrasquilla G, Porras A, Galera-Gelvez K, Lopez Yescas JG, Rueda-Gallardo JA. The burden of dengue and the financial cost to Colombia, 2010-2012. Am J Trop Med Hyg. 2016;94(5): 1065-72.
31. Ministerio de la Protección Social de Colombia. Guía para la atención clínica integral del paciente con dengue. Bogotá: MPSC; 2010.

32. Almond J, Clemens J, Engers H, Halstead S, Khiem HB, Pablos-Mendez A, et al. Accelerating the development and introduction of a dengue vaccine for poor children, 5 - 8 December 2001, Ho Chi Minh City, VietNam. Vaccine. 2002;20(25-26):3043-6.

33. Baly A, Flessa S, Cote M, Thiramanus T, Vanlerberghe V, Villegas E, et al. The cost of routine Aedes aegypti control and of insecticide-treated curtain implementation. Am J Trop Med Hyg. 2011;84(5):747-52.

34. Beauté J, Vong S. Cost and disease burden of dengue in Cambodia. BMC Public Health. 2010;10:521.

35. Carrasco LR, Lee LK, Lee VJ, Ooi EE, Shepard DS, Thein TL, et al. Economic impact of dengue illness and the cost-effectiveness of future vaccination programs in Singapore. PLoS Negl Trop Dis. 2011;5(12): e1426.

36. Kay BH, Tuyet Hanh TT, Le NH, Quy TM Nam VS, Hang PVD, et al. Sustainability and cost of a community-based strategy against Aedes aegypti in northern and central Vietnam. Am J Trop Med Hyg. 2010; 82(5):822-30

37. Stahl H-C, Butenschoen VM, Tran HT, Gozzer E, Skewes R, Mahendradhata Y, et al. Cost of dengue outbreaks: literature review and country case studies. BMC Public Health. 2013;13:1048.

38. Suaya JA, Shepard DS, Chang M-S, Caram M, Hoyer S, Socheat D, et al. Costeffectiveness of annual targeted larviciding campaigns in Cambodia against the dengue vector Aedes aegypti. Trop Med Int Health. 2007;12(9):1026-36.
39. Packierisamy PR, Ng C-W, Dahlui $M$, Inbaraj J, Balan VK, Halasa YA, et al. Cost of dengue vector control activities in Malaysia. Am J Trop Med Hyg. 2015;93(5): 1020-7.

40. Tiga DC, Undurraga EA, Ramos-Castañeda J, Martínez-Vega RA, Tschampl CA, Shepard DS. Persistent symptoms of dengue: estimates of the incremental disease and economic burden in Mexico. Am J Trop Med Hyg. 2016;94(5):1085-9.

41. García G, González N, Pérez AB, Sierra B, Aguirre E, Rizo D, et al. Long-term persistence of clinical symptoms in dengueinfected persons and its association with immunological disorders. Int J Infect Dis. 2011;15(1):e38-43.

42. Stanaway JD, Shepard DS, Undurraga EA, Halasa YA, Coffeng LE, Brady OJ, et al. The global burden of dengue: an analysis from the Global Burden of Disease Study 2013. Lancet Infect Dis. 2016;16(6):712-23.

43. Constenla D, Armien B, Arredondo J, Carabali M, Carrasquilla G, Castro R, et al. Costing dengue fever cases and outbreaks: recommendations from a costing dengue working group in the Americas. Value Heal Reg Issues. 2015;8:80-91.

44. Aguiar M, Coelho GE, Rocha F, Mateus L, Pessanha JEM, Stollenwerk N. Dengue transmission during the 2014 FIFA World Cup in Brazil. Lancet Infect Dis. 2015;15(7): 765-6.

Manuscript received on 14 December 2017. Accepted for publication on 29 May 2018. 
RESUMEN

\section{Repercusiones económicas del dengue en América Latina y el Caribe: una revisión sistemática}

Objetivos. Evaluar las repercusiones económicas del dengue en América Latina y el Caribe mediante una revisión sistemática que abarcó estudios no considerados en otras revisiones anteriores.

Métodos. Se usó la metodología de Cochrane para hacer una revisión sistemática del costo del dengue en América Latina. Se hizo una búsqueda en PubMed Central, EMBASE y la Biblioteca Virtual en Salud, que incluyen revistas científicas arbitradas no indizadas por otras bases de datos, desde su aparición hasta agosto del 2016. Se incluyeron todos los artículos que contenían datos sobre el costo de la enfermedad para los países de América Latina. Los estudios incluidos se sometieron a una evaluación metodológica para la cual se usó un instrumento de siete preguntas diseñado para los estudios sobre los costos de las enfermedades. Los datos extraídos fueron los costos directos e indirectos para los casos de pacientes ambulatorios y hospitalizados y el costo total de la enfermedad. Los valores se ajustaron a dólares de los Estados Unidos del 2015 con base en el índice de precios al consumidor.

Resultados. De un total de 848 referencias iniciales, se incluyeron 17 estudios, principalmente de Brasil, Colombia, Cuba, México y Puerto Rico; se encontraron datos sobre los costos en 39 países. La evaluación metodológica indicó que $70 \%$ de los estudios reunían más de 70\% de los puntos evaluados. La principal repercusión económica del dengue se debió a los costos por pérdida en la productividad. El costo anual promedio fue de más de USD 3.000 millones. Los costos directos representaron más de $70 \%$ del total para los casos de pacientes hospitalizados. En cuanto a los pacientes ambulatorios, los costos médicos directos fueron bajos, pero los costos sociales fueron considerables, ya que los costos indirectos pueden representar hasta $80 \%$ del costo total.

Conclusiones. El dengue tiene importantes repercusiones económicas en América Latina. Es fundamental elaborar nuevas intervenciones en materia de salud pública, como la vacunación contra el dengue, para reducir la propagación de la enfermedad y su costo total.

Palabras clave
Dengue; costo de enfermedad; costos de la atención en salud; América Latina; Región del Caribe. 
RESUMO

Impacto econômico da dengue na América Latina e Caribe: revisão sistemática
Objetivos. Avaliar o impacto econômico da dengue na América Latina e o Caribe por meio de uma revisão sistemática que incluiu estudos não considerados anteriormente por outras revisões.

Métodos. Utilizou-se a metodologia Cochrane para realizar uma revisão sistemática do custo da dengue na América Latina. Foi realizada uma busca dos bancos de dados PubMed Central, EMBASE e Biblioteca Virtual em Saúde- a qual inclui periódicos científicos com avaliação por pares não indexados por outros repositóriosdesde sua criação até agosto de 2016. Todos os artigos que relataram dados de custo de doença para países da América Latina foram incluídos. Os estudos incluídos foram submetidos a uma avaliação metodológica usando um instrumento de sete perguntas desenvolvido para estudos de custo de doença. Os dados extraídos foram os custos diretos e indiretos para casos ambulatoriais e hospitalizados e o custo total da doença. Os valores foram ajustados para dólares de 2015, usando-se o índice de preços ao consumidor.

Resultados. De 848 referências inicialmente identificadas, 17 estudos foram incluídos, principalmente do Brasil, Colômbia, Cuba, México e Porto Rico; dados sobre custos estavam disponíveis para 39 países. A avaliação metodológica demonstrou que $70 \%$ dos estudos apresentavam mais de $70 \%$ dos itens avaliados. O principal impacto econômico da dengue foi devido aos custos de produtividade. O custo médio anual foi superior a US\$3 bilhões. Para casos que exigiram hospitalização, os custos diretos representaram mais de $70 \%$ do custo total. Para pacientes ambulatoriais, os custos médicos diretos foram baixos, mas os custos sociais foram significativos, pois os custos indiretos podem representar até $80 \%$ do custo total.

Conclusões. A dengue tem impacto econômico considerável na América Latina. É essencial desenvolver novas intervenções de saúde pública, como a vacinação contra a dengue, para diminuir a propagação da doença e seu custo total.

Palavras-chave Dengue; efeitos psicossociais da doença; custos de cuidados de saúde; América Latina; Região do Caribe. 